\title{
The Current Mental Health Crisis of COVID-19 Pandemic Among Communities Living in Gedeo Zone Dilla, SNNP, Ethiopia, April 2020
}

\author{
Chalachew Kassaw $\cdot$ Digvijay Pandey $\mathbb{D}$
}

Received: 11 June 2020/Accepted: 17 August 2020/Published online: 25 August 2020

(C) Springer Nature India Private Limited 2020

\begin{abstract}
The current COVID-19 pandemic is not still controlled around the world and affects all humans' domains of day to day life. Peoples have killed themselves due to the fear of stigma by their community. This study aimed to assess the current mental health crisis of the COVID-19 pandemic among communities living in, Gedeo zone, Dilla, Ethiopia. The study was community based cross sectional design conducted from March 10-Apr 10, 2020, using a multi stage sampling techniques. Structured interview, Depression, Anxiety and Stress Scale (DASS-21), and logistic regression analysis (95\% CI, $p$ value <0.05) was used. This study included 420 respondents who were living in the Gedeo zone. In total, $44.4 \%$ of respondents had a psychological problem (21.4\% mild and $23 \%$ moderate level of the mental crisis). Gender female, monthly income below $500 \mathrm{ETB}$, and more than three family size were variables associated with the outcome variable $(p<0.05)$. Nearly half of the respondents had mild to the moderate mental crisis in response to
\end{abstract}

C. Kassaw $(\bowtie)$

Department of Psychiatry, College of Health Science, Dilla University, P.O. Box 419, Dilla, Ethiopia

e-mail: 1234berekassa@gmail.com

D. Pandey

Department of Technical Education, IET, Dr. A.P.J.

Abdul Kalam Technical University Uttar Pradesh,

Lucknow 226021, India

e-mail: digit11011989@gmail.com the pandemic. It is better to give mental health support for the peoples living in the zone to enhance their mental resilience.

Keywords Anxiety $\cdot$ Depression $\cdot$ Stress $\cdot$ Corona virus $\cdot$ Dilla $\cdot$ Ethiopia
Abbreviations
AOR
Adjusted odd ratio
CI
Confidence interval
COR
Crude odd ratio
COVID-19 Consider Coronavirus Disease 2019
DAAS
ETB
Depression, Anxiety and Stress Scale
KAP
Ethiopian birr
Knowledge, awareness, and practice

\section{Introduction}

The pandemic is continuing as the world health organization day to day work throughout the day due to its fast transmission and kills many million peoples around the world [1].

In Africa, more than nearly one million cases, 20,000 death, and in Ethiopia 17, 530, and 274 death were reported until this time [2]. The virus is too contagious and transmits to humans through contact of humans and surface, and symptoms were cough, fever, fatigue, breathing difficulty [3]. The Ethiopian 
ministry of health is working on the prevention of the virus at the country level by transmitting the media about the method of prevention, distributing face masks, sanitizers, and soaps [4].

During the severe acute respiratory syndrome, almost half of the non- infected communities were suffering from a mental and psychological disturbance related to the unpredictable outbreaks that happened in the world [5].

The current pandemic causes hopelessness, depression, anxiety, and suicide in all communities, infected, infected, health professionals following a few days of the outbreak [6]. The study done in china was the highest magnitude (53\%) of them suffered from moderate to severe levels of the psychological problem [7].

Mental health services have been working to address the crisis through online, outpatient, and inpatient mental health services for all of the communities in need [8].

Despite this fact, there is no sufficient study done on these issues in low and middle-level countries.

Therefore, the purpose of this study was to determine the magnitude of mental health crisis and associated factors related to the pandemic. This study result might be vital for generating appropriate mental health crisis management policies and plan for responding to the impact of the infection.

\section{Methods and Materials}

\section{Study Area, Study Period and Study Design}

The study was a community-based cross-sectional design conducted at the Gedeo zone from MarchApril 2020. It has a total population of 847,434 , of whom 424,742 are men and 422,692 women, and $359 \mathrm{~km}$ far from Addis Ababa (the capital city of Ethiopia, the main road from Addis Ababa to Kenya crosses.

\section{Eligibility Criteria}

The inclusion criteria of this study were respondent's age 18+ and able to listen and respond with either of the local languages, Amharic, or Gedeoffa local languages. The exclusion criteria of this study were those who weren't able to listen to the questions asked and not present during the data collection period due to different reasons (not in the house during the data collection period, acutely or severely ill).

\section{Sample Size Calculation}

The sample size was calculated using a single proportion formula population. We used the $p$ value of the previous study done in China 53.8\% [7].

$$
\begin{aligned}
\mathrm{P} & =0.54 \%, \text { Where, } \mathrm{n}=\text { required sample size } \mathrm{n} \\
& =\mathrm{Z}(\alpha / 2) 2 \mathrm{pq} / \mathrm{d} 2, \mathrm{p}=0.54 \\
& =(1.96)(1.96)(0.54)(0.46) /(0.05)(0.05)=382
\end{aligned}
$$

where $\mathrm{z}$ is the reliability coefficient at a $95 \%$ confidence interval (1.96)

$\mathrm{W}($ margin of error $)=0.05$ and $\mathrm{N}=$ non-response rate $10 \%=38$.

The final total sample size was, $382+38=420$.

Sampling Technique and Procedure

The sampling technique of this study was a multi-stage random sampling. Gedeo zone has seven woredas, Namely, Bule, Dilla town, Dilla zuria, Gedeb, kochere, Wenago, and Yirgacheffe. It has 179,677 households. At first, we selected all woredas in the zone. Then, we proportionally allocate to each kebeles of the hose holds found in the woredas. To select each household of the kebeles, we used simple random sampling and lottery method.

\section{Data Collection Tools}

The first part of the questioner is about the sociodemographic characteristics of respondents.

The second part of the questioner was about the mental health crisis and assessed using the Depression, Anxiety and Stress Scale (DASS-21) a 21- item Likert scale and sored $<30$ (Normal), 30-43 (mild) and 43-59 (moderate) $>60$ (severe) [9].

The third part of the questioner was about knowledge, attitude, and practice regarding the coronavirus, which has 12-items and scored as a continuous variable. The higher score is good knowledge [10].

Variables

Dependent variable—-mental health crisis 
Independent variables- Age, sex, educational status, occupational status, family size, and monthly income, and KAP about COVID-19.

\section{Data Collection Procedures}

First we carefully designed the questioner then we trained data collectors, supervisors for about four days about the aims of the study by considering the value of privacy and confidentiality. Each day the supervisors were checked the data about its completeness.

\section{Data Quality Control}

The pretest was done on the $5 \%$ populations before two weeks of the actual data collection period.

The questioner translated into the Amharic and Gedeoffa language and back-translated to English to check the consistency. The Amharic and Gedeoffa version questioner used for data collection.

Data Processing and Analysis

Data was entered into the Epi-Data 3.4 software package and exported to the Statistical Package for Social Science version 22. Descriptive statistics such as frequencies, percentages, graphs, and tables used to describe the data.

Logistic regression analysis used to determine the predictor variable of outcome variable at (95 CI and $p$ value $<0.05)$.

\section{Result}

Sociodemographic Characteristics Result of the Respondents

Nearly two-thirds of respondents had more than three family sizes and the average mean monthly income was 300 ETB (Table 1).

Knowledge, Attitude and Practice About Corona Virus

Nearly half of the respondents have no information about the signs and symptoms of the coronavirus. More than two-thirds of the respondents were not using a face mask when they leave their homes. Two- third of the respondents were frustrated about the control of the virus in Ethiopia.

Mental Health Crisis

$44.4 \%$ of the respondents were reported mild to moderate psychological problem.

Factors Associated with Psychological Problem

Variables associated with the outcome variable during bivariate and multi-variant logistic regression at $95 \%$ CI were female gender, less 300 ETB monthly incomes, and more than three family size. The odds of being a female's gender 2.32 times $(95 \% \mathrm{CI}, 1.32-$ 4.56) more likely to develop mental health problems in response to the pandemic.

Monthly income less than 300 ETB 4.56 times (95\% CI, 2.13-6.76) more likely to experience psychological problems.

The last variable contributing to the psychological problem was having more than three family size 2.34 (95\% CI 1.23-4.09).

\section{Discussion}

This study found $44.4 \%$ of the respondents were reported mild to moderate psychological problems in response to COVID 19 pandemic.

This study finding was lower than the study done in China in response to the COVID-19 epidemic which was $53.8 \%$ [7]. It might be due to the difference in culture, literacy, mental health service, resources for controlling the pandemic.

This study found that being females increase 2.32 times (95\% CI, 1.32-4.56) than males for developing psychological problems in response to the pandemic. This study was supported by the study done in Italy [11] and china [7]. It might be due to their natural lowlevel tolerance to stress and new situation. In-addition females in this study area are highly responsible for marketing and caring for the family.

This study found that the odds of monthly income less than 300 ETB has 4.56 times (95\% CI 2.13-6.76) more likely to experience psychological problems as compared to their counterparts.

This finding was similar to the study done in SaudiArabia [12]. The economic crisis the pandemic is 
Table 1 Socio-

demographic characteristics results of respondents living Gedeo zone, SNNP

Ethiopia $2020(\mathrm{~N}=420)$

\begin{tabular}{llcc}
\hline Variable & Category & Frequency $(\mathrm{n}=420)$ & Percentage $(\%)$ \\
\hline Sex & Male & 181 & 43 \\
Marital status & Female & 230 & 57 \\
& Single & 48 & 11.4 \\
& Married & 286 & 68.1 \\
& Divorced & 46 & 11 \\
Educational status & Widowed & 40 & 9.5 \\
& Primary & 176 & 42 \\
& Secondary & 134 & 31.9 \\
Occupation & More-than secondary & 110 & 26.1 \\
& Private job & 80 & 19 \\
& Farmer & 222 & 53 \\
Family size & Government job & 118 & 28 \\
& One & 34 & 8 \\
& Two & 97 & 23 \\
& Three and above & 289 & 68.9 \\
\hline
\end{tabular}

significant in low-income countries to the extent unable to buy preventive measures including soaps and facemask.

This study investigates that having more than three family size increase the chance of experiencing psychological problems by 2.34 times $(95 \%$ CI 1.23-4.09) than those who are alone. This study was consistent with the study of India [13]. The number of family sizes might contribute to an economic crisis to fulfill the daily needs of each family. Moreover, the family size increases the chance of contact with different people for contracting the virus from others.

\section{Limitation of the Study}

As the study used a cross-sectional study design, no conclusions can be drawn regarding causality and alternative explanations of the findings and cannot be ruled out.

\section{Conclusion}

This study found that as there is a mental health crisis in the community living in the Gedeo zone, SNNP, Ethiopia. The most affected populations were female, low-income, and family size.

Therefore it is better to work on the psychological wellbeing of the community through teaching how to handle the crisis of the pandemic during limited resources. The government should supply soaps and face masks for those who weren't able to buy in the community.

There should be a sustainable mental health task force for handling the psychological crisis of the pandemic in the community.

Acknowledgements The author would like to thank the clients who participated in the study and Dilla University and Gedeo zonal health center.

\section{Compliance with ethical standards}

Conflicts of interest The author declares no potential conflicts of interest concerning the research, authorship, and publication of this article.

Ethics approval and consent to participate Ethical clearance gained from the ethical review board of Dilla University and zonal health beauro. The written informed consent obtained from the respondents.

\section{References}

1. Heymann DL. A novel coronavirus outbreak of global health concern. Lancet Psychiatry. 2020;395:15-8.

2. Level R, Level G, High V, High V, High V. Coronavirus disease 2019 (COVID-19). 2020;2019(March).

3. CDC. Symptoms of Coronavirus (COVID-19). Cdc [Internet]. 2020;317142. Available from: https://www.cdc.gov/ coronavirus/2019-ncov/symptoms-testing/symptoms.html.

4. MOH. The Federal Democratic Republic of Ethiopia Ministry of Health Ethiopia COVID-19 Emergency Response 
Project ENVIRONMENTAL and SOCIAL COMMITMENT PLAN (ESCP). 2020;(March):1-9.

5. Peret T, Emery S, Tong S, Urbani C, et al. New Engl J. 2003;1953-66.

6. Ahmed Z, Ahmed O, Aibao Z, Hanbin S, Siyu L, Ahmad A. Epidemic of COVID-19 in China and associated Psychological Problems. Asian J Psychiatr. 2020;51:102092. https://doi.org/10.1016/j.ajp.2020.102092.

7. Cullen W, Gulati G, Kelly BD. Mental health in the COVID-19 pandemic. QJM. 2020;113(5):311-2.

8. Li W, Yang Y, Liu Z, Zhao Y, Zhang Q, Zhang L, et al. Progression of mental health services during the COVID-19 outbreak in China. Int J Biol Sci. 2020;16(10):1732-8.

9. Nordin RB, Kaur A, Soni T, Por LK, Miranda S. Construct validity and internal consistency reliability of the Malay version of the 21-item depression anxiety stress scale (Malay-DASS-21) among male outpatient clinic attendees in Johor. J Med J Malas. 2017;72(5):264-70.

10. Azlan AA, Hamzah MR, Jen T, Id S, Hadi S, Idsss A. Public knowledge, attitudes and practices towards COVID-19: A cross-sectional study in Malaysia. PLoS ONE. 2020. https:// doi.org/10.1371/journal.pone.0233668.
11. Moccia L, Janiri D, Pepe M, Dattoli L, Molinaro M, De Martin V, et al. Affective temperament, attachment style, and the psychological impact of the COVID-19 outbreak: an early report on the Italian general population. Brain Behav Immun. 2020;87:75-9. https://doi.org/10.1016/j.bbi.2020. 04.048 .

12. Alkwiese M, Alsaqri SH, Aldalaykeh M, Hamzi M, Mahdi $\mathrm{M}$, Shafie Z. Anxiety among the general population during Coronavirus-19 Disease in Saudi Arabia: implications for a Mental Support Program. medRxiv. 2020. https://doi.org/ 10.1101/2020.05.07.20090225v1.

13. Ahmad A, Nourah P, Abdulrahman B. Factors Influencing Mental Health During COVID-19 Outbreak: An Name of the Author 1: Absar Ahmad, PhD Name of the Author 3: Maitri Agarwal Current Affiliation: MBBS II nd year, Career Institute of Medical Science 2020.

Publisher's Note Springer Nature remains neutral with regard to jurisdictional claims in published maps and institutional affiliations. 